\title{
EXTENSION EDUCATION SYMPOSIUM: Getting the most out of your extension appointment and still having a life ${ }^{1}$
}

\author{
W. Powers, ${ }^{*}$ N. Cockett, $\uparrow$ and G. Lardy $\dagger_{\dagger}^{2}$ \\ *Office of the President, University of California, Oakland 94607; \\ $\dagger$ Department of Animal, Dairy and Veterinary Sciences, Utah State University, \\ Logan 84322-4815; and †Department of Animal Sciences, North Dakota State University, Fargo 58108-6050
}

\begin{abstract}
Managing the demands of an academic appointment in extension can be a challenging task. Demands from constituent groups, expectations of supervisors, and rigors of promotion and tenure processes can create pressures that young faculty did not expect. Throw in spousal and family duties and you have created a situation that many will find hard to navigate. However, there are ways to cope and, even better news, there are ways to excel in meeting the demands of an academic appointment and enjoying life. Because many new extension faculty members do not have prior experience in extension, best practices in documenting programs and extension scholarship over the pretenure period are provided in this paper. Appointments that include both research and extension are quite common at many land grant universities. The advantages of joint appointments are numerous and include the fact that more and more grant agencies are seeking integrated research, teaching, and/or extension projects. However, the time demands of joint appointments can be challenging. Joint appointments can be designed to help faculty members conduct important translational research and have it be applied in a production setting. By seeking commonalities in research and
\end{abstract}

extension efforts, joint appointments can be very synergistic. Development of highly successful programs requires planning on the front end with an emphasis on an in-depth needs assessment to determine stakeholder needs for both research and extension. Impact assessment should be part of this planning effort. Performing as a successful extension faculty member while maintaining relationships outside of work is challenging and requires deliberate effort on the part of employees and supervisors to realize there is more to life than work. Some authors have referred to this as work-life balance, but it may be more helpful to think of it as work-life effectiveness. To do this, one needs to 1) define what success looks like, 2) set boundaries and maintain control including control of your schedule, and 3) find time to ensure your physical, emotional, and spiritual well-being are nurtured in addition to your professional development. In summary, extension careers can be challenging at times as demands and expectations of stakeholders, supervisors, and rigors of the tenure system create formidable obstacles. However, by keeping a focus on the priorities of the position and looking for synergy in research and extension work, they can actually be quite enjoyable and very rewarding.

Key words: extension, joint appointments, life, needs assessment, tenure, work

\section{INTRODUCTION}

Academic positions, no matter what assignments are given to the faculty member, can be challeng-

\footnotetext{
${ }^{1}$ Based on presentations at the Extension Symposium titled "Growing Extension's Impacts with Changing Budgets and Personnel" held at the Joint Annual Meeting, July 19-23, 2016; Salt Lake City, UT, with publication sponsored by the Journal of Animal Science and the American Society of Animal Science.

${ }^{2}$ Corresponding author: gregory.lardy@ndsu.edu

Received December 2, 2016.

Accepted February 13, 2017.
} ing. Work demands and expectations are generally large and promotion and tenure processes seem to be more and more rigorous. Harris and Sullivan (2013) pointed out that even though faculty positions often have flexible schedules, the very nature of the flexibility can sometimes create negative situations when it relates to effectively managing work and life. As 
technology advances, we are increasingly connected to work in a virtual sense. We can be reached anytime, anywhere, with phone calls, text messages, and emails. This makes it harder to leave work at work and focus on family time when one has left the office. In addition, extension duties can often involve night and weekend work that better meets the needs of clientele (Kutilek et al., 2002). Some authors have suggested that worklife balance is not an effective term to describe the job satisfaction that we seek (Riordan, 2013). Instead they have proposed terms such as work-life effectiveness to better describe how to integrate work and home life while enhancing job satisfaction. In this manuscript, we give recommendations on how to be a successful extension faculty member, be more effective in joint extension/research appointments, and find more job satisfaction in your extension position.

\section{NAVIGATING THE TENURE AND PROMOTION PROCESS}

Decisions of tenure and promotion are a critical mechanism by which a university shapes its future. In addition, each tenure and promotion decision directly affects a faculty member's future in academia. It is imperative that there is clarity in expectations for a faculty position as well as the availability of "best practices" so that a faculty member can be successful in fulfilling those expectations. In some states, extension specialists are tenured within the academic college, whereas extension field staff members are tenured within their extension division. In other states, extension specialists can achieve tenure, whereas the field staff members do not have such processes or requirements. As an example, at Utah State University (USU; Logan, UT), the vice president for extension does not have direct authority over the decisions of tenure and promotion for extension specialists and there are annual performance review meetings for each specialist that include the extension administration, the department head, and the academic dean. This review provides the academic administration with insight on the performance of the specialists in his or her extension assignment. A single letter from the administration is returned to the faculty member so as to avoid mixed messages on performance.

Many universities, colleges, or departments have developed documents that articulate expectations for extension faculty and a framework for success under an extension assignment. These documents are used not only by faculty members and their direct supervisors to set goals and review performance but also by others, such as the university's central tenure and promotion committee, who are not familiar with the extension specialist role assignment.
Expectations in Extension. The major areas of expectation for extension faculty include program development and scholarship. Expectations for program development include the identification of needs and issues that lead to the development of programs that disseminate research-based information to citizens and communities. Extension specialists should develop long-term programs that have measurable outcomes and impacts. In addition to strong working relationships with extension field staff, extension specialists should emphasize partnerships with community, county, and state leadership. Specialists should use all of these contacts when developing or assessing extension programs. The value of an extension faculty member's major programs can be measured by the number of participants or contacts across years and the resulting impacts of the programs, such as change in behavior, dollars saved, dollars generated, or societal benefits. Specialists should collect participation and impact data across the program's timeline, including baseline or "benchmark" information and statistics that can be used for demonstrating growth and impacts over time. The number of major programs for each faculty member should increase during the pretenure period, but programs that have met objectives and clientele needs should be rotated out and replaced with new or emerging programs. Each major program should have a collection of support materials or outputs that can be used by clientele for expanding or refreshing their information, such as fact sheets, curriculum materials, and websites.

Extension specialists demonstrate scholarship through the dissemination of materials such as journal articles, fact sheets, web sites, decision support tools, curriculum materials, and presentations and abstracts at professional meetings. To be considered as scholarship, these outputs should be reviewed by appropriate peers, who are chiefly other extension specialists, extension field staff, researchers with applied programs, or other experts. The value of scholarship can be determined using standard measurements such as journal impact factors, citations, invitations for presentations, participation on working groups, and/or recognition through awards. However, the value of extension scholarship can also be measured by the uptake or adoption by other extension professionals. External funding can be considered a necessary input for developing scholarship and programming, a measurable component of scholarship, and/or a reflection of the extension faculty member's impact and reputation. The requirements for and evaluation of scholarship, including external funding, should be articulated at the beginning of the faculty member's pretenure period. Appropriate venues and approximate numbers of outputs should be established at that time.

Tenure and Promotion Portfolio. A portfolio of an extension specialist's programming and scholarship can 


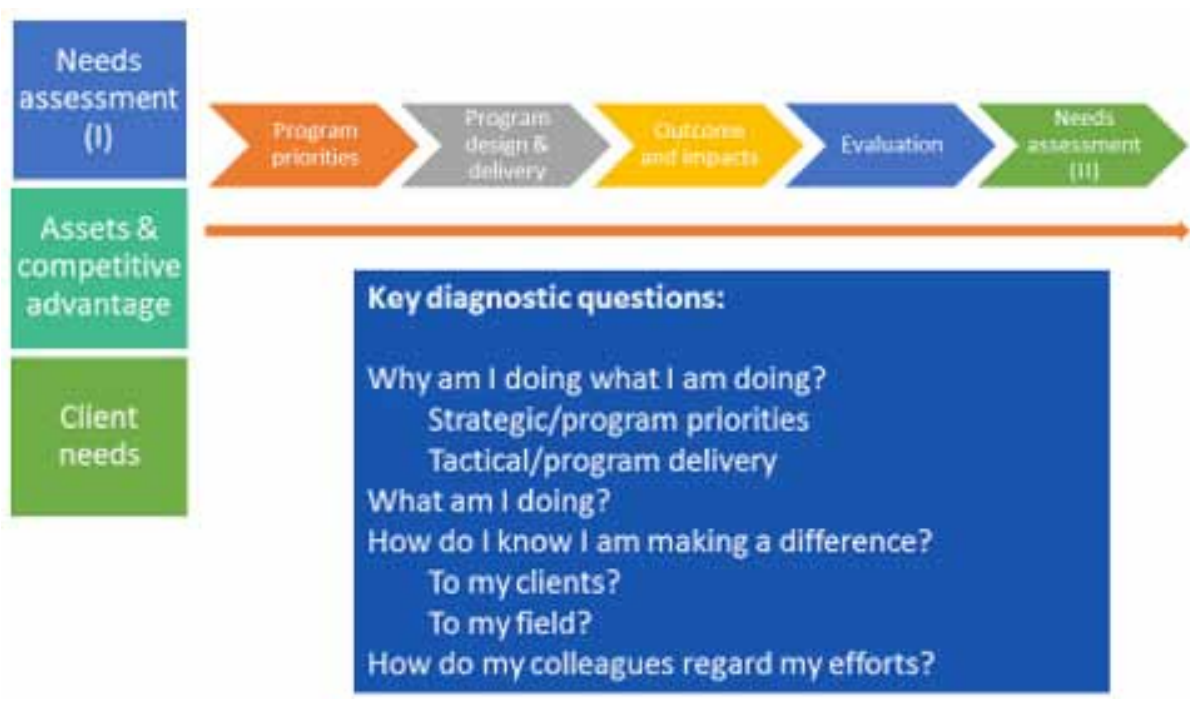

Figure 1. Development of a self-assessment document for extension at Utah State University. Design credit to Kristine Saunders, Utah State University.

be used for tenure and/or promotion evaluation. The specialist's portfolio at many universities includes a self-assessment document, a current curriculum vita, and separate documentation for each of the faculty member's assignments (extension, research, teaching, and/or service). The self-assessment document is framed around the Logic model (http://fyi.uwex.edu/programdevelopment/logic-models/; Fig. 1), including an assessment of the specialist's major programs based on clients' needs; the programs' priorities, design, and development; the specialist's outcomes and impacts; and evaluation of the programs. Modifications to programs should be done based on additional needs assessments.

Topics that should be addressed in the self-assessment document include "Why am I doing the things I am doing?" "What am I doing?" and "How do I know I am making a difference?" A good rule of thumb for the length of the self-assessment document is something that is readable in a single setting. The writer should assume that the readers have little to no experience with extension but that on reading the document, the readers should have a good understanding of the specialist's passion and purpose as well as the successes of the specialists' programs.

The tenure and promotion portfolio generally includes a curriculum vita. The curriculum vita is a summary of the faculty member's academic career, including education, employment history, and lifetime achievements or experiences such as awards, honors, professional organizations and assignments, publications, presentations, grant and contract funding, teaching assignments, mentored students, committee assignments, etc. The curriculum vita is continually updated and most commonly arranged by topical areas in descending or ascending order.

The extension documentation is an expanded listing and descriptions of the specialist's major programs. Each program should include a reflection on the need, intended audience, and strategic and tactical decisions in developing and delivering the program. Each program should also include tables with number of activities and participants by year, supporting activities (those delivered by others involved in the major program), impacts (compared with the base or benchmark year), and outputs (fact sheets, curriculum materials, websites, etc.). Impacts might also be documented in a bullet format. Details on "adoption" can also be included for each major program, listing the extension personnel in counties, states, and/or countries who have obtained and implemented a major program based on the specialist's original design. Volunteer recruitment and participant numbers ascribed to paid professions under the direction of the specialist can also be summarized for each major program.

In many cases, the extension document also lists scholarship attributable to the extension assignment. Scholarship under extension is those products that are used by extension peers as they develop their own programs or consider changes to the extension profession. Many of these outputs will already be listed in the curriculum vita but additional information can be included in the scholarship documentation, such as the role of coauthors, student participation, impact factors of journals, article citations, downloads, visits to websites, commercialization or technology transfer, awards for specific publications or presentations, etc. Contracts and grants that contribute to extension programming can also be listed, separated by internal and external sources and designated as funded, pending, or unfunded. A listing of all extension awards and honors should also be included, thereby demonstrating another measurement of the faculty member's reputation among peers.

The final section of the extension document should cover assessment of client needs as well as participant 
and peer evaluations and reflection on changes made to programs based on those evaluations. Extension specialists and faculty provide university service in addition to outreach, which may result in the inclusion of a service document separate from the extension document or within the extension document. Activities listed under service include assignments to the university and professional organizations by virtue of being a faculty member. Assignments based on a specialist's areas of expertise are viewed as part of the extension assignment and, therefore, are listed within the extension documentation.

Roadmap for Success in an Extension Assignment. Many pretenure faculty members with extension assignments do not have prior extension experience. Therefore, USU has developed a "roadmap" that describes approaches that can be used to develop major programs and scholarship during the pretenure period. The roadmap begins with the statement that an extension specialist provides the public, primarily within the state, with research-based information that is delivered through major programs in a particular area of expertise. These programs use a multifaceted approach that provides the information using innovative dissemination that reaches diverse audiences. The faculty member's major programs are designed as long-term, sequential sessions and are preferable to short-term, stand-alone activities because longer term, repeat programs are more effective at sustaining change and creating measurable impacts. The new extension specialist is also directed to document impacts of major programs using "benchmarks" early in the development of the program. These benchmark statistics can be compared with later data and participant numbers to monitor progress and impact. New faculty members are sometimes confused about the difference between impacts and outputs. Impact can be viewed as results, actions, or changes that occurred because of participation in the program whereas outputs are tangible products of the programs.

Throughout the United States, extension specialists are encouraged to work with field staff when developing, designing, marketing, and presenting programs and events. Long-term impacts and program exposure can be greatly expanded when specialists collaborate with field staff. These partnerships can result in scholarship that benefits both faculty members. Specialists are also encouraged to use volunteer and professional staff to extend outreach.

As the pretenure period progresses, extension faculty members should develop a professional reputation in his or her area of expertise that is centered around a focused and coherent theme. The extension specialist can establish this reputation among his or her peers by producing a steady stream of scholarship. At USU, scholarship has been broadly defined

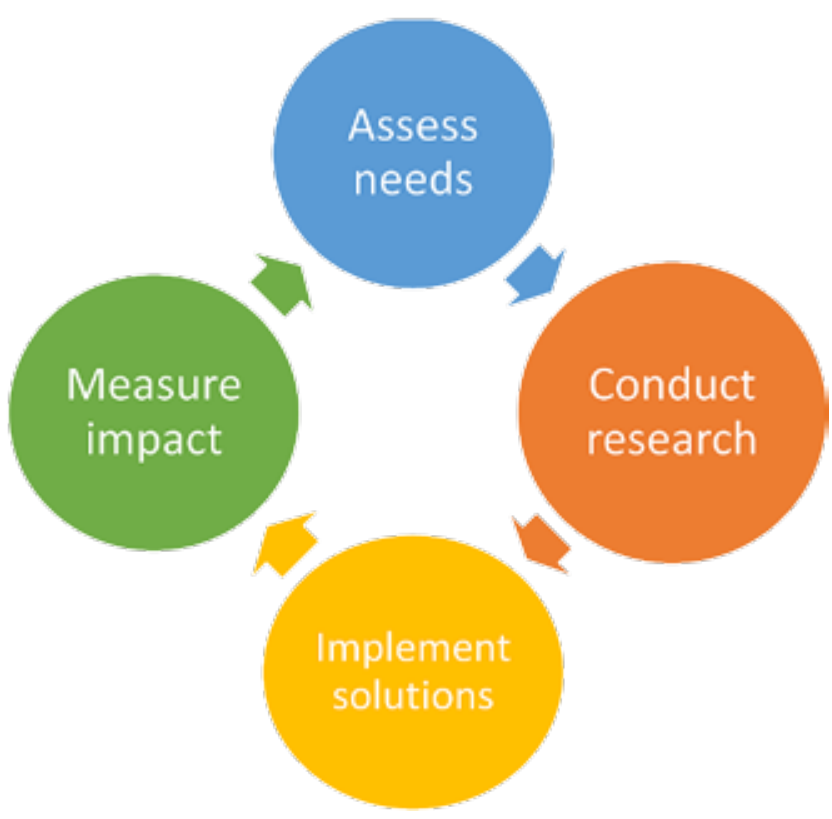

Figure 2. Components of an integrated research and extension program.

as the development or creation of extension materials that are disseminated through professional venues. It is particularly important that extension scholarship is validated for originality and quality through peer reviews. External validation can also be demonstrated by adoption by other extension personnel or the receipt of awards from extension professional associations at the state, regional, or national level. Examples of extension scholarship include the publication of case studies or curricula in peer-reviewed journals or in other peer-reviewed outlets, presentations of programs or curricula to peers at professional meetings, and external funding that supports major programs

\section{ENHANCING YOUR EXTENSION PROGRAM THROUGH A STRONG RESEARCH PROGRAM, AND VICE VERSA}

Increasingly, it is common that campus-based extension positions have joint appointment expectations, often across the research and extension missions, although extension and teaching appointments or even 3-way appointments exist among today's extension professionals. The concept is not new and has been referred to in the literature since the early 1970s (Florell et al., 1972). Faculty and, in a few states, advisors or other nontenured stream academics with joint appointments are successful in balancing and conducting joint research and extension programs. The extension and research missions are interwoven in that the purpose of applied research is to develop solutions to problems and the extension purpose is to translate discovery into practice (Fig. 2). Therefore, although successful integration of research and extension 
responsibilities may appear daunting at first, a well-funded research program contributes to impact-driven extension programming. Similarly, an extension program that is based on solid needs assessments seamlessly integrates into research support to develop and implement solutions.

Advantages of a Research and Extension Joint Appointment. Increasingly, competitive grants programs seek proposals that integrate the research and extension missions. Grantors are seeking projects that combine discovery research with behavioral, policy, or outcome changes that are measured or modeled as well as a strong justification of the work that is grounded in a convincing needs assessment. Although grant teams may be composed of individuals with single mission appointments, it is not uncommon for the resulting project to read as a research proposal where the extension component is completely independent or appears as though it was an afterthought. The joint appointment extension professional, or teams of them, may find greater success because proposals align with their own programmatic efforts that conceptualize, plan, and execute blended missions as opposed to writing a research project that reads as though the extension component was added on toward the end of the project duration. Extension professionals are clearly at an advantage in that they better understand what cooperative extension is and the impact extension programming has for clientele. As a faculty member with a joint appointment, in addition to serving as a change agent, one has the advantage of identifying and directing the needed science in order for change, and associated impact, to occur.

Extension and Teaching Joint Appointment. In some departments and institutions, joint appointments that blend the extension and teaching mission are also common. These appointments blend educational duties for both students and adult and/or youth extension audiences. Depending on the programming area and the intended audiences, one may find these joint duties almost seamless (e.g., youth audience programming and classroom expectations for college students). In other situations, employees may find it challenging to reach their extension audiences when they have traditional class meeting times (e.g., Monday, Wednesday, and Friday or Tuesday and Thursday classes), as a regularly scheduled class meeting times may not allow adequate travel time to reach stakeholder audiences. In large states, or in states where the campus is located on one side or the other, it may be difficult to balance the travel expectations and the classroom activities in a satisfying manner. However, with increasing emphasis on use of technology for program delivery, travel issues may be less of a problem. Regardless, it is important to recognize that each situation and position is different. Having clearly defined and reasonable expectations for joint appointments is important and cannot be overlooked.
Needs Assessment. Development of a successful and highly integrated research and extension program relies on careful and deliberate planning of activities such that the research and extension programs both complement and build on each other. Issue relevance provides a strong foundation for both resulting impact and funding alike. A formative evaluation process, including a needs assessment, can be used to determine how stakeholder needs relate to research questions that are addressed in requests for funding applications from competitive grants programs. Clear goals and objectives are imperative to a successful plan. Consider what the overarching problem is and how the overarching problem can be broken down into smaller researchable questions. Following that, one can develop a research plan to identify solutions to the individual research questions.

Translating Science into Practice. At the same time that research questions and plans are formulated, one should simultaneously identify strategies to convey the solutions to the end user. The very basic tools that increase awareness might include news releases, use of social media and newsletters, and other methods that increase awareness of the issue in your target audience. However, extension professionals must move beyond awareness toward methods that ultimately move individuals or groups to behavior change. Effective methods for sharing information that translates into implementation of recommended practices or other behavior changes might include demonstrations, summarized best practices, or tools that produce tailored recommendations. Delivery methods might include presentations, focus group meetings, web-based dissemination, and newsletter or other written media. Often a combination of methods is used to appeal to a wide array of users and improve uptake of the information. The extension professional must gauge how their intended audience would best receive information and consider how those methods compare with what approach is feasible given their own constraints. Consideration should be given to methods that are most influential in resulting in behavioral change; sharing knowledge is important, but the ultimate goal is to produce a behavioral or policy change that translates to an outcome or impact.

Impact Assessment. Development of a plan to translate the research findings into practice to solve problems includes a summative evaluation of the intended outcome and impacts that will result from adoption of practices and behaviors that are guided by the research findings. Identification of where a programmatic area will have measurable impact is key to development of a strong dossier as well as a strong factor for subsequent funding. Impact assessment is often one of the most difficult pieces of planning and evaluation of an integrated research and extension program. At the same 
time, quantifying impacts of an integrated research and extension program reflect strong scholarship, a critical criterion for promotion and continued funding support. Not every funded proposal or extension presentation will result in quantifiable impact. One should look at the larger, integrated research and extension programmatic effort and determine what the desired outcome of the larger effort is and what metrics serves as appropriate indicators of successful adoption and change and then focus on monitoring the metrics over time as the programmatic efforts accumulate.

Example metrics include adoption of practices or technologies coupled with research-supported change that results from implementation of the practice. Policy adoption that is based on the research serves as another metric. Other considerations for summative impact assessment include clear identification of the target audience and the appropriate time step for assessment of changes in that target audience, recognizing that this assessment time step may vary by audience. For example, if one were to conduct research that studied approaches to reducing the impact of livestock manure using nutrition and manure application methods, the extension efforts may be targeted toward multiple audiences such as consulting nutritionists, custom manure applicators, and policymakers. Impact assessment might include annual evaluation of feeding recommendations made by consulting nutritionists that produce changes in feeding practices and feed formulation to reduce excess dietary phosphorus. Using those data, the extension professional could calculate reduced phosphorus loads that could potentially move into surface water. Impact assessment that results for education provided to custom manure applicators might consist of surveys administered every other year to determine how often manure is applied to the same area and what methods are used to apply manure. The assessor could then use that information to quantify risk for nutrient movement to surface waters using available modeling tools. Policy changes over a longer time frame could demonstrate impact of programming if one has documented sustained research and extension programming activities that support the change in policy. Note that in each example provided, assessment is not performed for an isolated research project or extension activity but, rather, aggregation of activities over the course of a sustained time period to determine the measurable impact results from an extension program that has multiple deliverables over time (workshops, written communication, development of tools, policy briefings, etc.).

Balancing Research and Extension Efforts. Perhaps the biggest challenge in managing a joint appointment is finding a balance in how time is directed between research and extension efforts. Expectations can appear overwhelming in that each responsibility, research and extension, could be and is, for some individuals, a full-time effort. Often, joint appointments reflect specific expectations of effort (percent of time) devoted to each mission, although not all universities assign percentages to the missions when appointments are joint. Therefore, it is up to the faculty member to sort out the assignment and determine where to direct efforts, recognizing that between any given years, there will be some variation in how time and outputs occur. It is easy to get caught up in extension and research efforts that might not fit the overall extension and research priorities of the position all that well. Faculty should routinely ask the question "will this effort (extension or research) further the integrated mission of my position, help the constituent groups I am here to serve, or further the mission of my institution?" If the answer to these questions is "no," the faculty member should say "no" to the request. Although such activities do help one become recognized as a trusted resource, without clear goals and objectives, faculty can spend considerable time on extension activities that do not result in measureable impact at the expense of demonstrating a research trajectory and scholarship needed for promotion. To avoid this pitfall, faculty should stay focused on activities that align with a programmatic plan, that is, supported by the needs assessment with clear metrics for outcome and impact assessment as well as a strong connection to research scholarship. Indicators of scholarship include publications (peer-reviewed as well as end-user trade magazines), student involvement in projects, and development of tools in addition to research discovery, new knowledge dissemination through demonstrations and meetings, and funding procurement. The benefit of an integrated program is that when research activities are slow, one can focus on the extension programming aspect of the integrated program, and vice versa, thus ensuring a good use of time that translates into future opportunities to advance the program.

Through constant and deliberate focus on the interconnectedness of a research and extension program, faculty can balance a joint appointment and achieve intended outcomes and scholarly outputs that lead to career-long promotion in the academic system.

\section{HAVING A LIFE WITH AN EXTENSION CAREER}

The concept of work-life balance has appeared in the literature for many years and it is common to find references to the concept in both the public and private sectors. However, the definition of work-life balance 
has been elusive. The American Medical Association (2010) indicated that work-life balance translated to satisfaction with one's entire life, both professional and personal.

Harris and Sullivan (2013) indicated that achieving this state of contentment for academics is elusive, in part because of the very nature of our flexible work schedules. These authors also conceptualized balance as an alignment between one's use of time and personal and professional goals and priorities.

Alternative Theories. Clark (2000) proposed the concept of the work-life border theory in which the author proposed the idea that work and family systems, although different, are interconnected. The primary connection between these systems is human beings who make daily transitions between the 2 worlds. Ashkenas (2012) suggested that work-life balance is too simplistic, especially because it fails to reflect the nature of the digital age in which lines between work and personal life are often blurry.

The work-life balance theory is challenging, in part, because it may mistakenly imply that one dedicates equal portions of time to work and life. Riordan (2013) suggested that the concept should be referred to as work-life effectiveness rather than work-life balance. She suggested thinking of the concept as a holistic activity where one's career is an integral part of life rather than a separate and obligatory activity.

Work-Life Effectiveness for Extension Professionals. The concept of work-life balance is especially important for early career academics and those in tenure track positions. The pressures of starting a new job, meeting the demands of rigorous promotion and tenure processes, and, in many cases, beginning a family can seem overwhelming. It is important for those employees and supervisors to have open, honest communication regarding these pressures and to find effective ways to deal with all the demands on time that one can encounter in a tenure track position. It is common for early career professionals to have feelings of "I should be doing more" or "I need to work all the time." These feelings tend to lead to burnout and lowered job satisfaction. Kutilek et al. (2002) identified other factors related to careers in extension that can lead to work-life challenges. These include a generally heavy work load, many evening and weekend time commitments, and a feeling of lack of control or lack of job autonomy. In extension careers, there can be a feeling that one is not in control of your own schedule. Requests from constituency groups, stakeholders, and others can easily create situations where one feels guilty saying "No" or turning down requests for programming. These environments can also create stress at home because the spouse and family may not feel they are getting the time and attention they need or deserve as well. It can also create situations where the faculty member feels they are spending all their time at work.

Kutilek et al. (2002) also identified several spillover effects that result from work-life imbalance in extension careers. These include less time with family and friends, bringing work home, job-related stress, negative effects on family, and poorer employee health. These ultimately lead to negative effects on the organization due to lower job satisfaction, increased costs, and greater turnover in these positions.

Harris and Sullivan (2013) suggested that the fact that academics, in general, have more flexible schedules than many other occupations can lead to complications in achieving some sort of work-life balance or integration because of the very fluid boundaries that exist between work and home, especially with the technology that allows us to reach or be reached for work/related activities anytime, anywhere. In addition, they also noted that faculty positions commonly result in long hours and night and weekend work. Extension positions are no exception and, in many instances, are even more driven toward expectations of night and weekend work because of the schedules and availability of the audiences and constituency groups for which the program is intended.

\section{Recommendations for Supervisors and Employ-} ers. Given the potential negative situations that can develop when people feel an "imbalance" between their work and life, we have the following recommendations for supervisors and employees. First of all, supervisors need to take time to review existing policies related to work-life balance. Are they effective? Are they having the desired effects? If the answer to either of these questions is "no," then it is time to take steps to develop and implement policies that support work-life effectiveness. Supervisors should also role model effective behaviors. For example, if the supervisor states that "family time is important and you should attend your children's activities" but does not take time to attend their own children's activities, employees will be confused and left wondering whether or not the supervisor truly means that family time is important and what the consequences might be if they do take the time for their family activities.

Supervisors also need to work with employees to develop mutual expectations for work and family life. It is also important to remember priorities can and do change as family situations change. What might have worked well before an employee had children might not work well when they begin having children or when the children become active in school activities. Kegan and Lahey (2013, p. 319) stated in the book 
Immunity to Change that "people bring their humanity to work with them every single day." It is important for supervisors to be keenly aware that work and home are intertwined and they are very difficult to separate. Stressful situations at home will spill over into work and vice versa.

Recommendations for Employees. Employees should 1) define what success looks like, 2) set boundaries/maintain control, and 3) find time to ensure your physical, emotional, spiritual, and intellectual wellbeing is nurtured. Related to defining success, employees should determine in their mind "What does a successful extension professional look like?" and "What does a successful parent or spouse look like?' It is quite likely that these images of success might change over time. For example, what a successful parent of a newborn looks like is going to be different than what a successful parent of a teenager might look like. Furthermore, success to a young single faculty member may look different than the definition of success for a young faculty member who is starting a family.

Related to setting boundaries and maintaining control, employees should remember that this does include your schedule. To reduce the stress associated with scheduling conflicts, employees should get family and personal events on your calendar as soon as possible. Be sure to schedule some personal time as well. Increased stress can also occur when every available minute of the calendar is scheduled. Be sure to include some open time in your calendar for the inevitable last-minute things that come up. This will reduce the stress that occurs when things go wrong or last-minute requests come up.

It is also important for employees to determine with their supervisor how they will deal with worklife balance issues. Ideally, mutually agreeable expectations will be developed that ensure that work needs are met at the same time that the employee feels they can devote adequate time to family activities.

Many employees, especially new hires, may not have family obligations. This does not mean that time they spend away from work is any less valuable to their personal satisfaction and positive work experiences than employees who are married and/or have children (McGregor, 2013). Single employees and those without family duties also need time away from work obligations to recharge and refresh. These employees should not overlook both the value and the need for this time. Married or single, with or without family obligations, employees who feel they can get away from job duties and unwind from work-related stress almost always have better long-term work performance than those who do not.
Lastly, employees should take care of themselves. This includes making time to ensure your physical, emotional, spiritual, and intellectual well-being is nurtured. Questions you might ask yourself include "When do I feel my best?" and "When do you perform your best work?" These will help you schedule time for important tasks. If you are at your best in the mornings and you have a big project coming up, be sure you are putting time in your calendar to work on that project in the mornings as opposed to other times of the day that are less than optimal. Taking care of yourself should also include an emphasis on professional development. Take time to read and stimulate your intellectual curiosity. In extension, our clientele expect that we are staying on top of our professional development so that our extension programs reflect the latest in scientifically sound recommendations. This requires an extension professional to schedule time to read new research and not just develop extension programs.

\section{SUMMARY AND CONCLUSIONS}

Extension careers can be challenging at times as demands and expectations of stakeholders and supervisors and rigors of the tenure system create formidable obstacles. Joint appointments, when focused by a strong needs assessment for research, extension, and/or teaching efforts, can be quite effective. Administrators are encouraged to develop and communicate clear expectations related to the promotion and tenure process. Clear expectations will help the tenure track candidate develop a strong portfolio and body of work as they progress in their career. Being successful in joint appointments requires careful and deliberate planning. Faculty members are encouraged to conduct an in-depth needs assessment related to their job description. This will give them a clearer pathway and it will allow them to say "Yes" to the things that are important and turn down or diminish activities that are not as important or critical to their success. Related to improving work-life effectiveness and job satisfaction, one needs to 1) define what success looks like, 2) set boundaries and maintain control including control of your schedule, and 3) find time to ensure your physical, emotional, and spiritual well-being is nurtured in addition to your professional development. Extension professionals should keep a focus on the priorities of the position and look for synergy in research and extension work. In doing so, they are more apt to find these positions to be quite enjoyable and very rewarding. 


\section{LITERATURE CITED}

American Medical Association. 2010. Achieving work-life balance: More than just a juggling act. http://www.amednews. com/article/20100104/business/301049968/4/. (Accessed 18 October 2016.)

Ashkenas, R. 2012. Forget work-life balance: It's time for worklife blend. Forbes. http://www.forbes.com/sites/ronashkenas/2012/10/19/forget-work-life-balance-its-time-for-worklife-blend/\#7df456483e2f. (Accessed 1 November 2016.)

Clark, S. C. 2000. Work/family border theory: A new theory of work/family balance. Hum. Relat. 53:747-770. doi: $10.1177 / 0018726700536001$

Florell, R. J., R. P. Lora, and L. R. Robison. 1972. Joint appointments-Pros and cons. https://joe.org/joe/1972spring/19721-a5.pdf. (Accessed 4 November 2016.)
Harris, B., and A. L. Sullivan. 2013. Work-life balance in academic careers. http://apadivision16.org/wp-content/ uploads/2015/12/TSP-Vol.-67-No.-2-April-2013.pdf. (Accessed 18 October 2016.) p. 23-26.

Kegan, R., and L. L. Lahey. 2013. Immunity to change. Harvard Business Press, Boston, MA.

Kutilek, L. M., N. L. Conklin, and G. Gunderson. 2002. Investing in the future: Addressing work/life issues of employees. https://joe.org/joe/2002february/a6.php. (Accessed 20 October 2016.)

McGregor, J. 2013. Single, childless and want work-life balance? How taboo. https://www.washingtonpost.com/ national/on-leadership/single-childless-and-want-worklife-balance-how-taboo/2013/03/06/c0fc9750-8672-11e29d71-f0feafdd1394 story.html?utm term=.092872cfe39f. (Accessed 1 February 2017.)

Riordan, C. M. 2013. Work-life "balance" isn't the point. https:// hbr.org/2013/06/work-life-balance-isnt-the-poi. (Accessed 18 October 2016.) 